\title{
Relationship between Flexibility of Learning, Support Services and Students' Attitude towards Distance Learning Programme in Nigeria
}

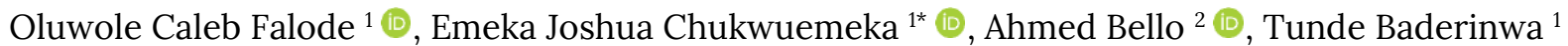

${ }^{1}$ Department of Educational Technology Federal University of Technology, Minna, Niger State, NIGERIA

${ }^{2}$ Department of Science Education, Federal University Kashere, Gombe State, NIGERIA

*Corresponding Author: emekac.joshua@gmail.com

Citation: Falode, O. C., Chukwuemeka, E. J., Bello, A., \& Baderinwa, T. (2020). Relationship between Flexibility of Learning, Support Services and Students' Attitude towards Distance Learning Programme in Nigeria. European Journal of Interactive Multimedia and Education, 1(1), e02003. https://doi.org/10.30935/ejimed/8320

\begin{abstract}
This study examined the relationship between flexibility of learning, support services and students' attitude towards distance learning programme in Nigeria. Correlational research design was adopted and 385 participants constituted the sample of the study using a multi-stage sampling procedure. The instrument used for data collection was a researchers-designed questionnaire comprising of three sections. The questionnaire was validated by experts and administered once on the randomly selected sample to determine the internal consistency of the items. Cronbach Alpha formula yielded 0.74, 0.77 and 0.78 for the three different constructs of the questionnaire. Two research questions were raised and two corresponding null hypotheses were tested at 0.05 level of significance. Data gathered were analysed using Mean, Standard Deviation and Pearson Product Moment Correlation formula. The results obtained reveal a positive correlation between the flexibility of learning and students' attitude towards distance learning programme $(\mathrm{r}=0.439, \mathrm{p}<0.05)$. Also, there was a positive correlation between support services and students' attitude towards distance learning programme $(\mathrm{r}=0.334, \mathrm{p}<0.05)$. It was therefore recommended among others that providers of distance learning programmes should ensure high flexibility and quality learner support services in order to cater for academic needs of learners with different characteristics as these would enhance students' positive attitude and improve the enrolment of candidates for distance learning programmes.
\end{abstract}

Keywords: distance learning, flexibility of learning, student support services, attitude

Received: 1 May $2020 \bullet$ Revised: 22 May $2020 \bullet$ Accepted: 24 May 2020

\section{INTRODUCTION}

Higher Education (HE) is considered as the spine of any society longing for development especially in the pace of 21st century. That is why international debate on HE centres on quality in education provisions, digitization, access and innovations as impediments for its development especially in developing countries like Nigeria (Kaplan \& Haenlein, 2016). While innovations in education can check quality concerns, digitization can increase access to education specifically at the level of HE. In Nigeria, HE entails post-secondary education obtained at Universities, Polytechnics, Monotechnics, Colleges of Education, as well as institutes that prepare candidates for professional courses. These institutions provide highly specialized training courses adapted to the needs of economic and social life of its citizens to satisfy the vision of Nigeria which recognises education as a public good, a fundamental human right that should be inclusive and equitable. The vision is also in line with UNESCO, (2016) provisions which require that HE be open to all so as to cater for the various aspects of lifelong education in the widest sense.

Consequently, these provisions are not easily met because of the predominant factors such as demography, the changing needs and dynamics of labour market and the paucity of supportive infrastructure that can accommodate students. These factors continue to mount pressure on the existing HE infrastructure which exceeded the brim and carrying capacity of those institutions yearly. Confirming this is the Ministerial Strategic Plan 2016-2019 yearly reports which stated that only about 17 per cent of those seeking placement in higher institutions in Nigeria are admitted (National Planning Commission, 2017). Adamu (2017) described this situation as a significant crisis in the education system that requires urgent attention of all stakeholders. Alternatively, UNESCO (2016) have tendered solutions to curb the applicants' upsurge into university education to include; the use of Information and Communication Technology (ICT) to increase flexibility in modes of study through distance learning and delivery of instructions through elearning. 
ICTs are diverse set of technological tools and resources used to communicate, create, disseminate, store, and manage information. ICT provide new means for content dissemination and user interaction, both with the content and the learning platforms in a more dynamic learning environments (Lytridis et al., 2018). With these provisions of ICTs, modern students often referred to as "digital natives" (those who were born in the era of digital technology) only require supportive devices to study educational content distantly. Thus, Falode, Bello, and Aje (2019) enumerated ICTs needed to support a dynamic teaching and learning in $\mathrm{HE}$ to include computers, internet, radio and television, digital camera, mobile devices and social media. To buttress the importance of these resources in HE, Alhih et al. (2017) stated that mediums provided by the technological tools that offer chances for students to share their ideas, talk and discuss or communicate should be made available for course delivery, interaction, evaluation and facilitation. To achieve this, course management platforms, accessible library resources, web cam, search engines and web sites are only some of the objects in the student-medium interaction that can facilitate a dynamic teaching and learning in HE. Apparently, universities equipped with needed ICT infrastructure stand a chance to excel ahead of their peers partly because, ICT is regarded as the most influential instrument for extending educational opportunities to all learners including low-income groups, girls and women. Mayanja, Tibaingana and Birevu (2019) added that physically challenged and students living in remote locations as well as those who for reasons of cost or time constraints are unable to enrol on campus can leverage ICT supported distance learning programs.

At present, distance learning programme provide an alternative for students whose work schedules are not compatible with the mainstream education and those who could not secure admission in a conventional university system. While this alternative will lighten the pressure inflicted on conventional universities infrastructure, it has also increased access to education and training provision by freeing learners from the barriers of time and place. Despite the increasing access to education, a large number of adult students might not be able to complete their study-due to other external factors, such as life commitments and unfamiliarity with new technology mediated learning environments (Lee et al., 2019). These categories of learners are those who could not meet up with strict regular university programs based of their peculiarities. However, since the institutionalization of ODL programme in Nigeria, students' enrolment, achievement and completion rate has not been as smooth as predicted especially when compared with those attending conventional university system (Balami $\&$ Sakir, 2014). For instance, antecedents of students' enrolment such as attitude toward ODL, intrinsic motivation to enrol and environmental and social conditions that facilitate enrolment are hidden factors petting for empirical investigation. Conversely, flexible learning schedules in ODL programme perpetrate higher achievements among students while support services such as availability of ODL administrators and technical assistants facilitate completion rate (Mburu, 2017).

In understanding acceptance factors toward enrolment in ODL, students' attitude is the key. For example, students had to evaluate factors such as flexibility of learning and support services available in ODL program before attitude formation which could later translate in to accepting to enrol. Attitude refers to the degree to which students has a favourable or unfavourable evaluation of distance learning programme. To measure students' attitude toward accepting to enrol in ODL programme, researchers capture indicators that represent the underlying construct such as cost, digital learning environment, online feedback and instructors' positive behavior. As Ajzen and Fishbein (1980) put it, attitude is determined by three components: attitude toward the behaviour (accepting to enrol in ODL program), behavioural beliefs (beliefs about programs' flexibility and support services available) and outcome evaluation. Thus, attitude toward enrolment in ODL program could be influence by students' subjective judgement of its flexibility to allow for online interaction with peers and tutors and their overall experience with prior learning programs. For instance, student motivation towards learning and assessment of the programs flexibility have been identified as critical to determine their acceptance of ODL which go a long way to influence attitude formation (Mburu, 2017).

Flexibility of learning (FL) in ODL program is distinct as a selfpaced mode of learning in which individual learner have the opportunity of choosing the most appropriate time, place, pace and resources suitable for their learning needs (Alice et al., 2016; Khan, 2007). Flexibility of learning in ODL program is often the most attractive feature contributing to students accepting to opt for this path over a more conventional education. This is because, it allows for more self-control and support students to advance their skills which they can later implement within their workplaces. Similarly, being able to demonstrate that they have learned these skills through ODL can contribute to students obtaining salary increment, bonuses and promotion to senior positions in their respective workplaces. Reasons advanced in favour of flexible Learning are that it is learner-centered and encompasses interactive learning environments facilitated by internet and digital technologies (Alice et al., 2016). However, these reasons might be difficult to achieve without a functional student support services made available at ODL to timely respond to students queries.

Student support services are cluster of facilities and activities that are provided in ODL program to make the learning process easier and more interesting to learners. They interface between the institution and the learner by providing adequate and timely support on questions arising from students regarding admission process, registration policies, tutor support, assistance on e-library and ICTs. Kaur (2016) refer to these support services informative to students in taking decisions on whether to enrol on ODL program or retract from enrolment. Additionally, Mburu (2017) is of the view that any deficiency in the provision of these services will lead to students being off balance and ill inform about the nature of ODL program either before or after enrolment. Furthermore, these deficiencies are not unrelated to students' low enrolment and completion rate of ODL programs. Support services inform students about the nature and flexibility of learning available in the program which could ultimately stimulate students' attitude formation toward accepting to enrolled in the program.

Several researchers like Mburu (2017) carried out a study on factors influencing learners 'attitude towards Distance learning programmes in Kenya: the case of ODeL campus, University of Nairobi with reference to Diploma in Adult Education and Community Development programme. The study adopted a descriptive survey design. Split half method was used to determine reliability of the questionnaires. Data was analysed both qualitatively and quantitatively. The findings revealed that most distant learners are adults employed and with family commitments. Instructional materials mostly used are the modules with 
little use of online materials. Alice et al. (2016) who found out that flexibility of learning enables educators to safely expose students to diverse actors, activities, and contexts through established curricula. Further, flexibility approaches lend themselves to diverse assessment strategies that allow students to demonstrate learning in multiple ways.

Likewise, Alhih et al. (2017) evaluate the levels of interaction in the practices of distance education centers. The sample of the study comprises of four teaching staff working at the Distance Education Centre and 36 undergraduate students at their 7 th semester studying in the Computer and Instructional Technologies Education department of the same center. Judgmental sampling from the non-random sampling methods has been used in the study. The study design was a mixed method research model employing survey from quantitative methods and case study from qualitative methods. The instrument was interaction and satisfaction Survey used to collect quantitative data while content analysis was used to analyze the qualitative data. The quantitative data was analyzed using percentage (\%) and frequency to gain a general insight about the interaction levels in distance education. The demographic data from the survey was analyzed through $t$-test and ANOVA for 3 or more variables. The findings from the student-student interaction section showed that the average responses of male and female students to interaction are similar to each other. There is no significant difference between male and female students' perceptions regarding student-student interaction. However, the results from the interviews with the teaching staff revealed a flexibility in studentcontent interaction in synchronous mediums which occur through content shared; different media tools used and posts during the course.

Mayanja, Tibaingana and Birevu (2019) conducted a study on the use of ICTs in student support in Open and Distance learning (ODL) at Makerere University. The study adopted a survey design with 327 ODL students, and the data from participants was collected using selfadministered questionnaires and individual interviews. The results showed that Makerere University has enhanced student learning and support through the introduction of learning management systems, web-based applications, registration, and result viewing to ensure students' satisfaction and retention in the ODL system. Another similar study was carried out by Kaur (2016) on student support services provided by authorities for improving the functioning of Open and Distance Learning. The result showed that majority of the students were not satisfied with the support system provided to them. The findings also revealed that students demanded regular revision in the curriculum according to the changing needs of the society, preferred knowledge with skills, addition of books in library and good support system for disabled students.

Afify (2018) conducted a study on the Impact of Interaction between Timing of Feedback Provision in Distance E-Learning and Learning Styles on achieving Learning Outcomes among Arab Open University Students. The sample consisted of (67) students from the Arab Open University, Kingdom of Saudi Arabia, Dammam Branch. The participants were divided into four experimental groups according to the design Factorial $(2 \times 2)$ : Group 1: $(19)$ students with active learning style provided with immediate feedback; Group 2: (17) students with active learning style provided with delayed feedback; Group 3: (15) reflective students provided with immediate feedback; Group 4: (16) reflective students provided with delayed feedback. The tools include observation card, satisfaction scale with e-learning environment and learning style scale. The results showed statistically significant differences between the mean scores of the experimental groups, which received immediate feedback in acquiring the design and production skills of blogging and satisfaction with e-learning environment. The results also showed that students with active learning style were superior in their performance on each of the performance practical skills for the design and production of blogs and satisfaction with e-learning environment.

\section{STATEMENT OF THE RESEARCH PROBLEM}

One of the major problems facing higher education in Nigeria bothers on how to cater for students' massive enrolment in higher institutions. The inability of these conventional universities to cater for the admission needs of all qualified candidates, coupled with the desire of individuals who need to further their education brought about the consideration of open and distance institutions such as National Open University of Nigeria as a worthy alternative. It is one thing to be admitted into distance learning institute, it is another thing to accept such admission as many unverifiable factors exist which hinders students from enrolling in open and distance learning programme.

Likewise, the success of a distance learner largely depends on the attitude towards the programme. As essential factors in open and distance learning which may influence either positive or negative attitude bothers on affordability in terms of cost, presence of digital learning environment, students support services and flexibility of learning. While some studies might have been conducted focusing on these factors, questions regarding reluctance in ODL enrolment and completion rate remained unanswered (Balami \& Sakir, 2014). Indeed, to the best knowledge of the researchers, no study has been carried out to determine the relationship between each of these factors and attitude towards ODL programme in Niger State. Hence, this study assessed the relationship between flexibility of learning, support services and students' attitude towards open and distance learning programme in Niger State, Nigeria.

\section{RESEARCH QUESTIONS}

The following research questions guided the study:

1. What is the relationship between flexibility of learning and students' attitude towards ODL programme in Nigeria?

2. What is the relationship between students' support services and their attitude towards ODL programme in Nigeria?

\section{RESEARCH HYPOTHESES}

The following null hypotheses were tested in the study:

HO1: There is no significant correlation between flexibility of learning and students' attitude towards ODL programme in Nigeria.

HO2: There is no significant correlation between students support services and their attitude towards ODL programme in Nigeria. 


\section{METHODOLOGY}

\section{Population and Sample}

This study adopted correlational research design. Correlational research design is a type of non-experimental research method in which a researcher measures two or more variables, understands and assesses the statistical relationship between them with no influence from any extraneous variable. The population for the study comprised of the entire 2,632 undergraduates of National Open University of Nigeria, Minna Study Centre, in the 2018/2019 academic session.

\section{Sampling Technique}

A multi-stage sampling technique was employed in selecting 385 respondents for this study. First, ODL Minna study center with eight faculties; Arts, Agriculture, Education, Health sciences, Management sciences, Sciences and Social sciences were purposively selected. Secondly, 385 students were randomly selected and proportionately based on the population of each faculty using Yaro Yamane's formula. The sampling procedure was employed to ensure that each of the faculty has enough students sample needed for this study.

\section{Instrument}

Open and Distance Learning Acceptance Factors Questionnaire (ODLAFQ) was developed by the researcher and used for data collection. The questionnaire was patterned into section A, B and C; with Section A consisting of 10 items related to flexibility of learning, Section B consisting of 10 items related to students support services while section $\mathrm{C}$ consisting of 10 items related to attitude of students toward ODL. A five-point rating scale of Strongly Agree (SA) awarded 5 points, Agree (A) awarded 4 points, Undecided (U) 3 points, Disagree (D) awarded 2 points and Strongly Disagree (SD) awarded 1 point was used. A grand mean score of 3.0 was used as a criterion for agreement or disagreement of each item responses. The instruments were validated by three educational technology experts at Federal University of Technology Minna and three ODL experts from National Open University of Nigeria, Minna study center. The experts checked the clarity, appropriateness and the suitability of the instrument for the targeted population. The inputs made by all the experts were integrated in to the instrument and a trial copy were produced for pilot study.

A pilot study was conducted on 15 students from National Open University of Nigeria, Minna study center, who were among the population, but not part of the sample that was used for the main study. The researchers carefully administered the instruments once on the respondents and the data obtained were analysed using Cronbach Alpha. Reliability coefficients obtained were 0.74 for flexibility of learning; 0.77 for students support service and 0.78 for attitude of students towards ODL respectively. Based on these reliability coefficient indexes obtained, the instruments were considered to have high and acceptable reliability. Alpha coefficients equal or above 0.70 are considered acceptable (George \& Mallery, 2003). To collect data for the main study, two persons were trained as research assistants and used for data collection. The completed copies of the questionnaires were collected by the researcher and subjected to descriptive and inferential statistics. The two research questions were answered using mean and standard deviation while the hypothesis was tested using Pearson Product Moment Correlation to determine the relationship between dependent variable and independent variable. The significant difference
Table 1. Mean and Standard Deviation of Respondents on Flexibility of Learning and Students' Attitude towards Open and Distance Learning

\begin{tabular}{|c|c|c|c|c|c|}
\hline Variables & $\mathbf{N}$ & $\overline{\bar{X}}$ & SD & $\mathbf{R}$ & Sig. \\
\hline Flexibility of Learning & 385 & 43.13 & 3.65 & \multirow{2}{*}{$.439^{* *}$} & \multirow{2}{*}{.000} \\
\hline Students' Attitude & 385 & 42.73 & 4.77 & & \\
\hline
\end{tabular}

Table 2. Mean and Standard Deviation of Respondents on Students' Support Services and their Attitude towards Open and Distance Learning

\begin{tabular}{cccccc}
\hline Variables & $\mathbf{N}$ & $\overline{\boldsymbol{X}}$ & SD & R & Sig. \\
\cline { 1 - 4 } Students Support Services & 385 & 42.83 & 4.51 & \multirow{2}{*}{$.334^{* *}$} & \multirow{2}{*}{.000} \\
\cline { 1 - 5 } Students Attitude & 385 & 42.73 & 4.77 & & \\
\hline
\end{tabular}

was ascertained at 0.05 alpha level. The Statistical Package for Social Science (SPSS) version 23.0 was used for the analysis.

\section{RESULTS}

Research Question One: What is the relationship between flexibility of learning and students' attitude towards ODL programme in Nigeria?

Table 1 shows the Mean and Standard Deviation of respondents on flexibility of learning and students' attitude towards open and distance learning. The table reveals $\bar{X}=43.13, \mathrm{SD}=3.65$ and $\bar{X}=42.73, \mathrm{SD}=$ 4.77 for the two constructs respectively. To determine whether the mean scores have any significant relationship, a corresponding null hypothesis was tested using Pearson Product Moment Correlation analysis. The hypothesis state that there is no significant relationship between flexibility of learning and students' attitude towards ODL programme in Niger State Nigeria. The table revealed a statistically significant positive correlation between flexibility of learning and students' attitude towards open and distance learning, $(r=.439, \mathrm{~N}=385$, $\mathrm{p}<.05)$. Thus, the hypothesis was not supported, implying that as long as there is Flexibility of Learning in ODL, students' attitude towards enrolling in to the ODL will improve.

Research Question Two: What is the relationship between students' support services and their attitude towards ODL programme in Nigeria?

Table 2 shows the Mean and Standard Deviation of respondents on student support services and their attitude towards open and distance learning. The table reveals $\bar{X}=42.83, \mathrm{SD}=4.51$. and $\bar{X}=$ $42.73, \mathrm{SD}=4.77$ for the two constructs respectively. To determine whether the mean scores have any significant relationship, a corresponding null hypothesis was tested using Pearson Product Moment Correlation analysis. The hypothesis state that there is no significant relationship between Students Support Services and students' attitude towards ODL programme in Niger State Nigeria.

The table revealed a statistically significant positive correlation between students support services and their attitude towards ODL programme $(r=.334, \mathrm{~N}=385, \mathrm{p}<.05)$. The hypothesis was not supported, implying that as long as students support services are available and functional in ODL, students' attitude towards enrolling in to the program will improve. 


\section{DISCUSSION OF FINDINGS}

The findings of research question one and the corresponding null hypothesis revealed that there is correlation between flexibility of learning and students' attitude towards ODL programme in Niger State and the correlation is significantly positive. The finding means that students' attitude toward enrolling in ODL program tend to increase with the increasing attention of stakeholders toward making the program more flexible for learners. This is because flexibility of learning helps students to engage with online study during their own chosen time and preferred location. Convincingly, this learning mode helps a learner with more independence to engage with autonomous learning based on their background, capabilities and interest. As learning continue this way, a more enhanced positive attitude towards ODL could be develop among students. The finding agrees with Alhih, et. al., (2017) whose study revealed a flexibility in student-content interaction in synchronous mediums which occur through content shared; different media tools used and posts during the course. The finding was also supported by the earlier finding of Alice et al. (2016) who found out that flexibility of learning enables educators to safely expose students to diverse actors, activities and contexts through established curricula.

The finding of research question two and the corresponding null hypothesis revealed that there is correlation between students support services and students' attitude towards ODL programme in Niger State and the correlation is significantly positive. The plausible reason for this finding is that if ODL programme focus more on increasing students support services, the overall image of the institution will be high and students' positive attitude toward accepting to enrol in the program will be stimulated. Similarly, an increase in student support services will amount to retention of the already enrolled ODL students and facilitate completion rate. This finding was supported by the earlier finding of Mayanja, Tibaingana and Birevu (2019) whose results showed that Makerere University has enhanced student learning and support through the introduction of learning management systems, web-based applications, registration, and results viewing to ensure students' satisfaction and retention in the ODL system. The finding was also supported by Afify (2018) whose results showed a statistically significant differences between the mean scores of the experimental groups, which were supported by immediate feedback in acquiring the design and production skills of blogging and satisfaction with distance e-learning environment. However, the finding was not supported by Kaur (2016) who revealed that majority of the students were not satisfied with the support system provided to them in higher education institutions as such they had negative attitude towards ODL.

\section{CONCLUSION}

Based on the above findings it can be concluded that there is a linear relationship between flexibility of learning in ODL program and students' attitude towards enrolling in to the program in Niger State, Nigeria. Thus, as ODL programme continue to be flexible through its student-content interaction in synchronous and asynchronous mediums, different media tools used and rapid response through posts during the course, students' attitude toward the programme would be positive. Similarly, it was also concluded that there is a linear relationship between student support services and their attitude towards ODL in Niger State, Nigeria. This conclusion arises from the fact that support services such as guidance services and immediate feedback deliver learners satisfaction about ODL programme which in turn sustain a positive attitude toward the programme.

\section{RECOMMENDATIONS}

1. To raise students' attitudes toward accepting to enrol in ODL, the administration of the programme in collaboration with program coordinators should work toward making the program more flexible so as to attract more students enrolment.

2. The program coordinators should improve on learner support services to cater for the different learner characteristics, support prospective students' queries so as to enhance a positive attitude towards ODL.

\section{REFERENCES}

Adamu, A. U. (2017, July 26). NOUN: Student population hits 400,000. Blueprint. Retrieved from https://www.blueprint.ng/nounstudents-population-hits-400000/

Afify, M. K. (2018). The Impact of Interaction between Timing of Feedback Provision in Distance E-Learning and Learning Styles on achieving Learning Outcomes among Arab Open University Students. Eurasia Journal of Mathematics, Science and Technology Education, 14(7), 3053-3068. https://doi.org/10.29333/ejmste/ 91619

Ajzen, 1., \& Fishbein, M. (1980). Understanding Attitudes and Predicting Social Behavior. Englewood Cliffs, N. J.: Prentice-Hall.

Alhih, M., Ossiannilsson, E., \& Berigel, M. (2017). Levels of Interaction Provided by Online Distance Education Models. Eurasia Journal of Mathematics, Science and Technology Education, 13(6), 2733-2748. https://doi.org/10.12973/eurasia.2017.01250a

Alice, C., Guopeng, F., Valley, W., Cyprien, L., Eduardo, J., \& Andrew, R. (2016). Flexible Learning Strategies in First through Fourth-Year Courses. University of British Columbia.

Balami, Y. G., \& Sakir, A. (2014). Determinants of Adult Learners Enrolment into Open and Distance Learning Institutions in the North East, Nigeria. Journal of Education and Practice, 5(31), 58-64.

Falode, O. C., Bello, A., \& Aje, D. E., (2019). Comparative Effects of Electronic and Printed Books on Biology Students' Achievement and Attitude towards Genetics Concepts in Colleges of Education in Niger State, Nigeria. Journal of Economic and Social Research, 18 (2), 106-115.

FRN. (2013). Federal Republic of Nigeria. National Policy on Education. Lagos: Federal Government Press.

Kaplan, A. M., \& Haenlein, M. (2016). Higher education and the digital revolution: About MOOCs, SPOCs, social media, and the Cookie Monster. Business Horizons, 59(4), 441-450. https://doi.org/10.1016/ j.bushor.2016.03.008

Kaur, S. (2016). Student Support Services in Higher Education: A Student Perspective. The International Journal of Indian Psychology, 3(9), 126-132. 
Khan, B. H. (2007). Flexible learning in an information society. Hershey, PA: IGI Global. https://doi.org/10.4018/978-1-59904-325-8

Lee, K., Choi, H., \& Cho, Y. H. (2019). Becoming a competent self: A developmental process of adult distance learning. The Internet and Higher Education, 41, 25-33. https://doi.org/10.1016/j.iheduc.2018. 12.001

Lytridis, C., Tsinakos, A., \& Kazanidis, I. (2018). ARTutor-An Augmented Reality Platform for Interactive Distance Learning. Education Sciences, 8(6), 1-12. https://doi.org/10.3390/ educsci8010006
Mayanja, J., Tibaingana, A., \& Birevu, P. M. (2019). Promoting Student Support in Open and Distance Learning using Information and Communication Technologies. Journal of Learning for Development, 6(2), 177-186.

Mburu, S. W. (2017). Factors Influencing Learners' Enrolment in Distance Learning Programmes in Kenya: A Case of University of Nairobi (Unpublished Master Thesis), University of Nairobi, Kenya.

National Planning Commission. (2017). The National ICT roadmap (20172020). Retrieved from http://www.niimp.gov.ng/?page_id=1218

UNESCO (United Nations Educational, Scientific and Cultural Organization). (2016). Global education monitoring report 2016: Education for people and planet, creating sustainable futures for all. Paris: United Nations Educational, Scientific and Cultural Organization. 